\title{
Elektronik Bilgi Kaynakları ve Bibliyografik Atıflar
}

\section{Electronic Information Sources and Bibliographic Citations}

\section{Selenay Aytaç}

\section{Öz}

Kısa bir süre öncesine kadar yararlanılabilecek bilgi kaynakları basıll materyallerle ( $k$ itap, dergi, rapor, vb. gibi) sinurlyyd; ancak bilgi teknolojilerindeki gelişmelerle kaynak çeşidinde de hızlı bir artıs yaşandı. CD-ROM, elektronik kitap, elektronik dergi ve Web sitesi gibi elektronik bilgi kaynakları sadece günlük yaşamımızda değil akademik araştırmalarda da kullanılmaya başlandı. Araştırma raporlarında elektronik ortamda bulunan kaynaklara nasıl atıf yapılacağı konusunda farklı görüşler öne sürülmeye başlandi ve farklı atı stilleri (APA, MLA, vd.) geliştirildi. Bu çallşmada elektronik ortamda buIunan elektronik kitap, elektronik dergi, web sayfası vb. gibi yayınlara nasıl atıf yapılacağı Amerikan Psikoloji Derneği'nin (APA) yayın kurallarından uyarlanarak örneklerie açıklanmaktadır.

Anahtar sözcükler: Bibliyografik atıflar, Elektronik bilgi kaynaklarına yapılan atıflar.

\section{Abstract}

Types of information resources were somewhat limited up until the last two decades. Researchers primarily used printed materials such as books, journals and reports. Along with the development of information technologies, the types of information resources have also proliferated. Electronic information resources in the form of $C D$ ROMs, electronic books, electronic journals and web sites have become an indispensable part of not only our daily lives, but also of academic life. Different style books (APA, MLA, etc.) offer different solutions as to how to cite electronic information resources in research reports. This paper summarizes the main points of citing

\footnotetext{
• Uzman Kütüphaneci, Işık Üniversitesi Kütüphane ve Dokümantasyon Dairesi Başkanlığı, Istanbul (selenay@isikun.edu.tr).
} 
electronic information resources by making use of the American Psychological Association (APA) publication style.

Keywords: Bibliographical citations, Citations of electronic information resources.

\section{Giriş}

Bilimsel nitelik ve niceliklere uygun olarak hazırlanmış çalışmalar, seçilmiş konu veya konular üzerindeki araştırmaları gösterir. Araştırma sonuçlandığında, entellektüel mülkiyet haklarına saygılı bir araştırmacının, yararlanılan kaynakları belirtmek için uygun atıf (gönderme, referans) biçimleri kullanması kaçınılmazdır. Metin içinde ve kaynakçalarda nasıı atıf yapılacağı konusunda Amerikan Modern Dil Derneği (MLA), Amerikan Psikoloji Derneği (APA), Biyoloji Editörleri Konseyi (CBE) gibi çeşitli kuruluşların atıf yöntemlerinden, ve çeşitli yazarların el kitaplarından yararlanılabilir (örneğin, bkz. Turabian, 1996).

Atıf (citation) kelime anlamı itibariyle, "bir eserden diğerine aktarma, iktibas; aktarılan bölüm" (Redhouse, 1993) anlamında kullanılmaktadır. Atıf, "kaynak olarak gösterme, gönderme"; atıtta bulunmak, "bir şeye göndermede bulunmak, göndermek, bir şeyi kaynak olarak göstermek"; gönderme yapmak ise, "bir yazıda bir konu işlenirken ilgisi dolayısıyla başka konu ya da konulara, kaynaklara yollamak" (Türkçe, 1995) anlamına gelmektedir.

Internet ve elektronik kaynaklara atıf yapmak için insani bilimlerde MLA ve Şikago Stili EI Kitabı, fen bilimlerinde APA ve CBE ve tarih alanında Turabian atıf yöntemleri kullanılabilir (Li ve Crane, 1996; Walker, 2000; Page, 1996; Carbone, t.y.). Araştırmalarda kullanılan atıflar hem özgün çalışmayı yapana saygıyı gösterir hem de asli bilgi kaynağına ulaşııması için gereken doğru ve kısa adresi vermiş olur. Bu çalışmada, atıflarda uyulıması gereken genel yazım ve ahlak kurallarına değinilmeyecektir. Amaç; uluslararası standartlardan APA stilini kullanarak elektronik kaynaklara nasıl atıf yapılacağını örneklerle açıklamaktır. 


\section{Elektronik Bilgi Kaynaklarına Yapılan Atıflar}

Elektronik biçimdeki bilgi kaynaklarına yapılan atıflar, basılı bilgi kaynaklarına yapılan atıflara göre bazı farklılıklar göstermektedir. Bu farklı atıf biçimlerinin hemen hemen hepsinde ortak temel unsurlar kullanılır. Buniar; yazar adı, eser adı, yayın yeri, yayınlayan, yayın tarihi ve kaynağın sayfa numarasıdır. Ayrıca çoğu atıf biçimleri bilgi kaynağına erişim tarihini (access date) ve bilginin saklandığı ortamı (medium) da bildirir.

Elektronik biçimdeki bilgi kaynaklarına yapılan göndermelerde karşılaşıIan bir diğer önemli husus ise bazı unsurların eksik veya başka terimlere çevrilmiş olabilmesidir. Örneğin, elektronik ortamda yazı yazan kişi takma adını veya kulıanıcı adını kullanabilir, yayın adı bölümünde de yalnızca elektronik kaynağın dosya adı bulunabilir.

Numaralandırmada da elektronik ve elektronik oimayan bilgi kaynakları arasında birtakım farklııılar olması kaçınılmazdır. Kararsız kalındığında yapılması gereken, gönderme bilgilerinin tümünün yazıımasıdır; çünkü böyle bir yöntem, eksik bilgi yazmaktan daha iyidir (Walker, 2000).

Bilgisayar ve telekomünikasyon teknolojilerindeki gelişmelerin birleşmesi, bilginin işlenmesi, iletilmesi ve depolanması bilgiye ulaşım olarak tanımlanan yeni bilim alanları ve teknolojiler doğurmuştur. Bunlardan birisi de Internet'tir. "Web tarzı çalışma" iş yapmanın sınırlarını değiştırmektedir. Web'in yaygınlaşmasıyla bağımsız profesyonellik, sporcuların ve sanatçıların tekelinden çıkmış ve tüm bilgi işçilerine açılmıştır. Internet artan bir hızla yayımlanan bilimsel belgelere kolayca ulaşma imkânı sağlamaktadır (Gates, 1999).

Araştırmacılar; Internet'te birçok kaynak aramakta, bulmakta ve kullanmaktadırlar. Ancak elektronik kaynaklar için dipnot ve kaynakça yazmaya teşebbüs ettiklerinde yeni problemlerle karşılaşmaktadırlar. Basılı kaynaklar için kullanılan basım tarihi, sayfa numarası gibi standartlar, elektronik kaynaklar için de kullanılmaya çalışıldığında bazı zorluklarla karşılaşabilmekteyiz. Çünkü elektronik kaynaklarda yayın tarihi ve sayfa numarası olmayabileceği gibi alışımamış parantezler de noktalama için gerekebilir. 
MLA ve APA gibi otorite kabul edilen profesyonel dernekler, elektronik bilgi kaynaklarına atıfta bulunulabilmesi için, bazı standartlar oluşturmaya başIamışlardır. Bu arada Melvin E. Page gibi bazı araştırmacılar da kişisel aktarma tarzlarını oluşturmaya girişmişlerdir. Profesör Page'in oluşturduğu aktarma biçimi "H-AFRICA" isimli elektronik haberleşme listesine gönderilmiş ve iki gün içinde de 30 ayrı haberleşme listesinde paylaşılmaya başlanmıştır (Guernsey, 1996).

Çalışmalarını Internet'te yayımlayan araştırmacıların itibar kazanmaları ancak diğer araştırmacıların onlara atıfta bulunmalarıyla mümkün olabilmektedir. Ancak, bu kaynaklara atıfta bulunmak oldukça zordur. Çünkü Internet kaynakları basılı kaynaklara oranla bibliyografik olarak belirgin farklılıklar göstermektedir. Bunun sonucunda da elektronik kaynaklar için yeni aktarma yöntemleri ołuşturulmasına veya var olan yöntemlerin değiştirilmesine gayret edilmiştir.

\section{Çözüm Önerileri}

Her elektronik bilgi kaynağında atıf unsurlarının tümü (örneğin, yayın tarihi) bulunmayabilir. (Yayın tarihi verilmemişse, basılı yayınlarda olduğu gibi, parantez içinde "tarih yok" veya "t.y." ibareleri kullanılır.) Özellikle kaynak olarak kullanılan web sayfalarına atıf yapılırken, kaynakça bilgilerini oluşturmak için gerekli bütün unsurlar ekranda görünmeyebilir. Burada Web sayfasını oluşturan hipermetin işaretleme dili (HTML) ile yazılmış kaynak kodu bazen kullanıcıya yardımcı olabilir. Web tarayıcı yazılım (Netscape Navigator veya Internet Explorer) aracılığıyla sayfa hazırlayıcısının dizinleme amacıyla kullandığı "metatag"lar görülebilir ve sayfanın başığı, yaratıcısı, yayın tarihi ile ilgili atıf ögelerinden bir ya da birkaçı elde edilebilir. Ancak söz konusu atıf bilgilerine erişmek için, sayfa hazırlayıcısının ya da yazarının kaynak koda çoğu bilgileri özellikle girmesi gerekmektedir.

Internet aracılığıyla erişilen kaynaklara yapılan atıflarda karşılaşılan bir başka önemli sorun da sıklıkla değişen, güncellenen, genişletilen ya da ya- 
yından kaldırılan web sitelerinin elektronik adreslerì (URL: Uniform Resource Locator) ile nasıl başa çıkılacağıdır. Zamanla elektronik adresi değişen bir bilgi kaynağına ulaşmak isteyen araştırmacı başarısızlığa uğrayacaktır. O zaman istenilen dokümana erişmek yerine sıkça tanık olunan "404 FILE NOT FOUND" (Dosya bulunamadı) uyarısı ile karşılaşılır. Bu durum hem araştırmacılar hem de bilgi teknolojileri uzmanları için sorun yaratmaktadır.

URL (Uniform Resource Locator) World Wide Web için bir adresleme sistemidir (Kennedy, 1999). Her Web sayfasının genellikle bir URL'si vardır. Örnek vermek gerekirse, http://www.unak.org.tr, Üniversite ve Araştırma Kütüphanecileri Derneği'nin URL adresidir. Kısacası URL, ulaşmak istediğimiz belgenin veya kaynağın Web adresidir.

Farklı URL adreslerine taşınmak veya yayından kaldırılmak suretiyle beklenen kaynağa ulaşamama gibi sorunların çözümü için araştırmacılara gönderme yöntemleri yardımcı olamaz. Bu durum elektronik kaynaklara yapılan atıflarda "erişim tarihi" ögesinin kullanımını gündeme getirmiştir. "Erişim tarihi" atıfta bulunulan elektronik kaynağa araştırmacının hangi tarihte Internet aracılığıyla eriştiğini göstermektedir. Araştırmacı atıf bilgilerinin hemen ardından, köşeli parantez içinde, web sitesini ziyaret ettiği yılı, ayı ve günü belirtir. Elektronik kaynakların yerlerinin sık sık değişmesi önlenemese bile Web sayfası sorumlularının web sitelerinde dikkatlice açıklamalar bulundurmaları ve gerekirse ilgili sayfayı arayan kullanıcıları bağlantılar (links) aracılığıyla yeni URL adreslerine yönlendirmeleri gerekir (Page, 1996).

\section{Amerikan Psikoloji Derneği Stiline Göre Elektronik Bilgi Kaynaklarına Yapılan Atıflar}

Amerikan Psikoloji Derneği (APA: American Psychological Association) atıf yöntemi kısaca "yazar - tarih" yöntemi olarak da bilinir. Metin içinde bir kaynağa atıf yapılırken, örneğin yukarıda verilen (Guernsey, 1996) örneğinde de görülebileceği gibi, yazar soyadı ve yayın tarihi verilir. Doğrudan alıntılarda 
sayfa numarası da verilir. Yazarı belirsizse eser adının ilk sözcüğü verilir. Yayın tarihi bulunamıyorsa parantez içinde (t.y.) ibaresi kullanılabilir.

Aşağıda APA stiline göre elektronik bilgi kaynaklarına yapılan atıflarda önce atıf ögelerinin sırası verilmekte, daha sonra da örneklerle kullanım biçimleri açıklanmaktadır. (Daha fazla örnek için Ek 1'de yer alan konuyla ilgili Web adresleri ziyaret edilebilir.)

\section{Tek Eserler}

- Yazar/Editör. (Yayın Yılı). Eser adı (basım), [Ortam türü]. Üretici firma (varsa). Sağlama adresi: Sağlayıcı Firma/Neri tabanı numarası [Erişim tarihi].

- Yazar/Editör. (Yayın Yılı). Eser adı (basım), [Ortam türü]. Üretici firma (varsa). Elektronik adres (varsa): Protokol://Site/Patika/Dosya adi [Erişim tarihil.

Örnekler

- Oxford English dictionary computer file: On compact disc (2nd ed.), [CDROM]. (1992). Sağlama adresi: Oxford UP [27 Mayıs 1995].

- Pritzker, T. J. (t.y.). An Early fragment from central Nepal [Çevrimiçi]. Elektronik adres: http://www.ingress.com/ astanart/pritzker/pritzker.html [8 Haziran 1995].

\section{Eserin Bir Bölümü}

- Yazar/Editör. (Yayın Yılı). Eser adı içinde (basım), [Ortam türü]. Üretici firma (varsa). Sağlama adresi: Sağlayıcı Firma/Neri tabanı numarası [Erişim tarihi].

- Yazar/Editör. (Yayın Yılı). Eser adı içinde (basım), [Ortam türü]. Üretici firma (varsa). Elektronik adres (varsa): Protokol:/Site/Patika/Dosya adt [Erişim tarihi]. 


\section{Örnekler}

- Bosnia and Hercegovina. (1995). Academic American Encyclopedia içinde [Çevrimiçi]. Sağlama adresi: Dow Jones News Retrieval Service/ENCYC [5 Haziran 1995].

* Bir ansiklopedideki yazarı bilinmeyen bir makale.

- Daniel, R. T. (1995). The history of Western music. Britannica online: Macropaedia içinde [Çevrimiçi]. Elektronik adres: http:/Www.eb.com:180/cgi-bin/g:DocF=macro/5004/45/0.html [14 Haziran 1995].

\section{Dergi/Magazin/Gazete Makaleleri/Yazllant}

- Yazar. (Yıl, Ay gün). Makale adı. Dergi/Magazin/Gazete ad, [Ortam türü], cilt(sayı), sayła no. ya da uzunluk bilgisi. Sağlama adresi: Sağlayıcı FirmaNeri tabanı adı (Varsa veri tabanı numarası)/Sağlama numarası [Erişim tarihi].

- Yazar. (Yıl, Ay gün). Makale adı. Dergi/Magazin/Gazete adı, [Ortam türü], cilt(say।), sayła no. ya da uzunluk bilgisi. Elektronik adres (varsa): Protokol://Site/Patika/Dosya adı [Erişim tarihi].

\section{Örnekler}

- Clark, J. K. (1993). Complications in academia: Sexual harassment and the law. Siecus Report [CD-ROM], 21(6), 6-10. Sağlama adresi: 1994 SIRS/SIRS 1993 SchoolNolume 4/Article 93A [13 Haziran 1995].

- Spink, A. and Xu, J.L. (2000, October). Selected results trom a large study of Web searching: the Excite study. Information Research [Çevrimiçi], 6(1). Elektronik adres: http://InformationR.net/paper90.html [20 Aralık 2000].

- Montgomery, C.H. (2000, October) Measuring the impact of an electronic journal collection on library costs: a framework and preliminary observations. D-Lib Magazine [Çevrimiçi], 6(10). Elektronik adres: http://www.dlib.org/dlib/october0o/montgomery/10montgomery.html [21 Kasım 2000]. 
- Tonta, Y. (1992). Analysis of search tailures in document retrieval systems: a review. The Public-Access Computer Systems Review [Çevrimiçi], 3(1): 4-53. Elektronik adres: http://info.lib.uh.edu/pr/v3/n1/tonta.3n1 [17 Haziran 2000].

- Schiesel, S. (1999, May 4). Nortel plans new product to bolster optical networks. The New York Times [Çevrimiçi], Elektronik adres: http://www.nytimes.com/library/tech/99/05/biztech/articles/04nortel.html [20 Ekim 1999].

\section{Web Siteleri}

Metin içinde bir web sitesine genel bir atıf yapılırken sitenin adresinin parantez içinde verilmesi yeterlidir. Örneğin, "Bilgi Dünyası dergisi hakkında ayrıntılı bilgi ÜNAK'In web sitesinden (http://www.unak.org.tr) edinilebilir." Web sitesinin adresi kaynakçada ayrıca verilmez. Web sitelerinde yer alan belgelere yapılan atıfflara örnek aşağıda verilmektedir.

- Yazar/editör. (Yıl). Belgenin adı. [Çevrimiçi ]. Elektronik adres: Protokol://Site/Patika/Dosya adı [Erişim tarihi].

- Tonta, Y. ve Küçük, M.E. (2000). Elektronik Kütüphanecilik Semineri: Bir değerlendirme. [Çevrimiçi]. Elektronik adres: http://yunus.hacettepe.edu.tr/-tontalyayinlar/tonta-kucuk.html [10 Aralık 2000].

\section{Tartışma Listelerine Gönderilen Mesajlar}

- Yazar. (Yıl, Ay gün). Mesajın konusu. Tartışma Listesi adı, [Ortam türü]. E-posta adresi: TARTIŞMA LISTESi@e-posta adresi [Erişim tarihi].

- Yazar. (Yıl, Ay gün). Mesajin konusu. Tartışma Listesi adi, [Ortam türü]. E-posta adresi: LISTSERV@e-posta adresi/Get [Erişim tarihi].

\section{Örnekler}

- TONTA. (3 Eylül 1991). TURKMARC. Kutup-/[Çevrimiçi]. E-posta adresi: KUTUP-L@metu.edu.tr [26 Haziran 2000].

*Yazarın kullanıcı adı büyük harfle ilk öge olarak verilir. 
- TONTA. (3 Eylül 1991). TÜRKMARC. KUTUP-L. [Çevrimiçi]. E-posta adresi: LISTPROC@Ometu.edu.tr/Get kutup-I log0991 [1 Ağustos 1995].

* Kutup"l listesi arşivine ilgili mesaj gönderilerek elde edildi.

Kişisel Elektronik Hetişim (E-posta)

Yazarın kişisel iletişim kurduğu kimselerden gelen elektronik posta mesajları metin içinde diğer kişisel iletişim mesajları gibi verilir. Örneğin, "M.E. Küçük'ün yazara gönderdiği elektronik posta mesajından (27 Eyiül 2000) anlaşıldığı kadarıyla Elektronik Kütüphanecilik Semineri..." Kişisel iletişim, kaynakçada gösterilmez.

\section{Sonuç}

Bu çalışmada elektronik bilgi kaynaklarına yapılan bibliyografik atıflar konusuna değinilmiş ve APA stili kullanılarak ilgili kaynaklara nasıl atıf yapılması gerektiği örnekler verilerek açıklanmıştır. Basılı kaynaklarda olduğu gibi, elektronik bilgi kaynaklarına atıfta bulunmanın temel sebebi okuyucuya kullanılan kaynak hakkında yeterli ve sistematik bilgi vermektir. Atıfta bulunmak istediğimiz elektronik bilgi kaynağ elektronik dergide yayımlanan bir makale olabilir. Elektronik kaynaklara atıfta bulunmak için, uluslararası düzeyde kabul edilen evrensel bir atıf biçimi henüz yoktur. Ancak, var olan yöntemler elektronik kaynaklara atıf yapmak için uyarlanmakta ve kullanılmaktadır . Araştırmacılar konularına göre, en uygun atıf biçimini kullanarak elektronik bilgi kaynaklarına atıf yapmaktadırlar.

Internet aracılığıyla erişilebilen kaynaklara yapılan atıflarda, basılı yayınlardan farklı olarak, o kaynağa hangi protokol (http, gopher, telnet, vd.) kullanılarak erişim sağlanacağı ve ilgili belgenin hangi sitede, hangi dizin altında ve hangi dosya adıyla saklandığı da belirtilmektedir. Bunun yanı sıra, atıf yapan araştırmacının ilgili dosyaya eriştiği tarih de künyenin en son ögesi olarak kullanılmaktadır. Böylece web ortamındaki belgelerin zaman içinde farklı 
adreslere taşınmasıından veya tamamen ortadan kalkmasından doğabilecek güçlükler erişim tarihi ögesinin kullanı/masıyla bir ölçüde gíderilmeye çalışı|mıştır.

Ülkemizde de son yıllarda mesleki literatürde yer alan bazı çalışmalarda elektronik bilgi kaynaklarına yapılan bibliyografik atıflara rastlanmaktadır. Ancak bu kısa makale, bildiğimiz kadarıyla, kütüphanecilik literatüründe konuyla ilgili olarak yapılan ilk çalışmadır. Daha geniş bilgi ve örnekłer için okuyucuların Ek 1'de verilen web adreslerini ziyaret etmelerinde yarar görülmektedir.

\section{Teşekkür}

Bu çalışmaya katkıda bulunan editör Doç. Dr. Yaşar Tonta'ya teşekkür ederim.

\section{Kaynakça}

Carbone, N. (t.y.). Citing electronic sources. [Çevrimiçi]. Elektronik adres: http://www.marlboro.edu/home/CitingElectronicSources.html [27 Eylül 2000].

Gates, B. (1999). Dijital sinir sistemiyle düşünce hızında çalışmak. (Çev. Ali Cevat Akkoyunlu). İstanbul: Doğan Kitapçılik.

Guernsey, L. (1996, Ocak 12). Cyberspace citations scholars debate how best to cite research conducted on line. The Chronicle of Higher Education, s. A18.

Kennedy, A.J. (1999). The Internet: The rough guide (4th ed.). New York: Rough Guides LId.

Li, X. ve Crane, N.B. (1996). Electronic styles: a handbook for citing electronic information (2nd ed.). Medford, N.J: Information Today, inc.

Page, M.E. (1996, Şubat 20). A brief citation guide for Internet sources in history and the humanities. H-AFRICA Humanities On-Line [Çevrimiçi]. Elektronik adres: http://www2.h-net.msu.edu/ africa/citation.html [19 Eylül 2000]. 
Redhouse English-Turkish Dictionary = Ingilizce Türkçe Redhouse Sözlügüu (20th ed.). (1993). Ed. Robert Avery. Istanbul: Redhouse Yayınevi.

Turabian, K.L. (1996). A manual for writers of term papers, theses, and dissentations (6th ed.). Ed. by John Grossman and Alice Bennett. Chicago: University of Chicago Press.

Türkçe sözlük. (1995). Ed. Ali Püsküllüoğlu. Isstanbul: Yapı Kredi Yayınları.

Walker, J. (2000, August 17). Style sheets for citing Internet \& electronic resources: Humanities (MLA \& Chicago), Scientific (APA \& CBE), and History (Turabian) [Çevrimiçi]. Elektronik adres: http:/wwww lib.berkeley.edu/TeachingLib/Guides/Internet/Style.html [21 Eylül 2000]. 


\section{Ek 1. Elektronik Bilgi Kaynaklarına Yapılan Atıflarla İlgili Bilgi İçeren Web Adresleri}

- American Psychological Association (APA). How to cite information from the Internet and the World Wide Web. Elektronik adres: http://www.apa.org/journals/webref.html.

- The B. Davis Schwartz Memorial Library. Citation style for research paper. Elektronik adres: http:/www.liunet.edu/cwis/cwp/library/workshop/citation.htm.

- International Organization for Standardization (ISO). Excerpts from ISO Draft International Standard 690-2 - Information and documentation Bibliographic references - Electronic documents or parts thereof. Elektronik adres: http:/www.nlc-bnc.ca/iso/tc46sc9/standard/690-2e.htm.

- Page, M.E. A brief citation guide for Internet sources in history and the humanities (Version 2.1). Elektronik adres:

http://www2.h-net.msu.edu/ a africa/citation.html.

- Walker, J.R. Style sheets for citing Internet \& electronic resources: Humanities (MLA \& Chicago), Scientific (APA \& CBE), and History (Turabian). Elektronik adres: http://www.lib.berkeley.edu/TeachingLib/Guides/Internet/Style.html. 